\title{
P-chirogenic phosphorus compounds by stereoselective Pd-catalysed arylation of phosphoramidites
}

\begin{abstract}
Anirban Mondal ${ }^{1,2}$, Niklas O. Thiel ${ }^{1,2}$, Ruth Dorel ${ }^{1}$ and Ben L. Feringa ${ }^{1}{ }^{\bowtie}$
The phosphorus stereocentre, present in a diversity of compounds ranging from phosphonates to phosphines, plays a crucial role in various fields, in particular catalysis, materials science, agrochemistry and drug development. The unique structural and stereochemical features of intrinsically homochiral phosphorus units form the incentive for major current efforts towards developing stereoselective synthesis methodology of P-chirogenic compounds. Despite advances in metal-catalysed C-P bond formation, generating homochiral phosphorus stereocentres remains challenging. Here we present an efficient and flexible method for the synthesis of various classes of P-chirogenic compounds through the functionalization of phosphonamidates with excellent stereoselectivity. Key to this is an asymmetric C-P cross-coupling reaction between phosphoramidites and aryl halides with axial-to-central transfer of chirality and the use of $1,1^{\prime}$-bi-2-naphthol as an inexpensive chiral auxiliary. Preliminary mechanistic studies revealed the formation of an unexplored chiral amino-phosphonium intermediate. This transformation sets the stage for ready access to P-chirogenic phosphinates, phosphine oxides and phosphines.
\end{abstract}

S ince the pioneering work by Knowles ${ }^{1,2}$ on catalytic asymmetric hydrogenations in the 1960s utilizing chiral monodentate tertiary phosphines as ligands, P-chirogenic compounds have emerged as key components in a range of asymmetric transformations ${ }^{3}$ including enantioselective transition-metal-catalysed hydrogenations $^{4}$, cross-couplings ${ }^{5-8}$, atroposelective $\mathrm{C}-\mathrm{H}$ activation ${ }^{9}$ and various organocatalytic reactions ${ }^{10}$. Despite an early focus on bidentate chiral phosphines, at the start of the new millennium Kagan initiated the renaissance of monodentate P-chirogenic ligands in asymmetric catalysis ${ }^{711-14}$. In addition to their prominent use in enantioselective catalytic transformations, other P-chirogenic compounds including phosphonates and phosphoramidates have also found widespread applications in materials science ${ }^{15}$, agrochemistry $^{16}$ and drug development ${ }^{17,18}$ with a major role in the area of oligonucleotide chemistry ${ }^{19}$. Phosphorus stereogenic centres can be found in the structures of prodrugs or pharmaceutically active compounds, an illustrative example of which is remdesivir, a drug that has recently gained major interest in light of the COVID-19 pandemic $\mathrm{c}^{20,21}$. For many years, the synthesis of P-chiral compounds has relied heavily on the resolution of racemates ${ }^{22-28}$. The introduction of chiral auxiliaries allowed some of the intrinsic limitations of chiral resolution to be addressed. Methods based on the use of P-resolved precursors with one or more leaving groups were developed initially using menthol ${ }^{29}$, ephedrine ${ }^{30,31}$ and subsequently terpenoid derivatives like camphor or recently trans-(+)-limonene oxide $^{32,33}$ as chiral auxiliaries. We envisioned that advances in metal-catalysed C-P cross-coupling reactions in recent years and their use in the preparation of non-chiral phosphines and phosphine oxides ${ }^{34-40}$ provides an attractive starting point to develop general catalytic methodology to access enantioenriched P-chirogenic compounds. To the best of our knowledge, a general and flexible method for an asymmetric $\mathrm{C}-\mathrm{P}$ coupling, starting from stable phosphorus(III) compounds remains challenging ${ }^{41-45}$. So far only one example, starting form chiral phosphine-boranes ${ }^{46}$ and a few studies using racemic secondary phosphine oxide $(\mathrm{P}(\mathrm{V}))$ have been reported ${ }^{47-49}$.

Following the introduction of chiral phosphoramidites by our group, and building on our longstanding efforts exploring these new classes of chiral ligands in asymmetric transformations ${ }^{50,51}$, we devised a general and divergent strategy for the preparation of P-chirogenic compounds based on the transition-metal-catalysed C-P cross-coupling involving $\mathrm{P}$-arylation of phosphoramidites (Fig. 1a). Advantageous is the ready access to chiral phosphoramidites, the use of the cheap and recyclable 1,1'-bi-2-naphthol (BINOL) chiral auxiliary, commercial aryl halides and triflates as coupling partners, common Grignard or organolithium reagents, high functional-group tolerance and the divergent and flexible nature of the protocol to provide a variety of chiral phosphorus compounds. We take into consideration that a Pd-catalysed P-arylation of BINOL-containing phosphoramidites will be likely to benefit from excellent stereocontrol, due to the proximity of the BINOL chiral auxiliary to the P-reaction centre taking advantage of axial-to-central chirality transfer. It is envisioned that $\mathrm{C}-\mathrm{P}$ cross-coupling by coordination of the phosphoramidite $\mathbf{A}$ to $\operatorname{Pd}(0)$ and subsequent oxidative addition of an aryl halide could generate key P-stereogenic aryl phosphoramidate B (Fig. 1a). In other words, we expect the axial chirality from BINOL to be transferred to central chirality located at phosphorus with high stereocontrol, avoiding the requirement of a chiral Pd catalyst. Next, sequential solvolysis to arylphosphonate $\mathbf{C}$ and $\mathrm{P}$-arylation/P-alkylation will remove the amine and BINOL auxiliary and provide chiral phosphine oxides allowing a divergent approach to various enantiomers (Fig. 1a). Mechanistically, following coordination of phosphoramidite and oxidative addition of aryl halide to $\operatorname{Pd}(0)$, reductive elimination of aryl Pd(II)-complex II could form an as yet unexplored phosphonium salt III (ref. ${ }^{52}$ ) (P(III) to $\mathrm{P}(\mathrm{V})$ transformation), as a result of new C-P bond formation (Fig. 1b). The newly formed phosphonium cation III would be electrophilic in nature at the

'Stratingh Institute for Chemistry, University of Groningen, Groningen, the Netherlands. ${ }^{2}$ These authors contributed equally: Anirban Mondal, Niklas O. Thiel. 凶e-mail: b.l.feringa@rug.nl 
a

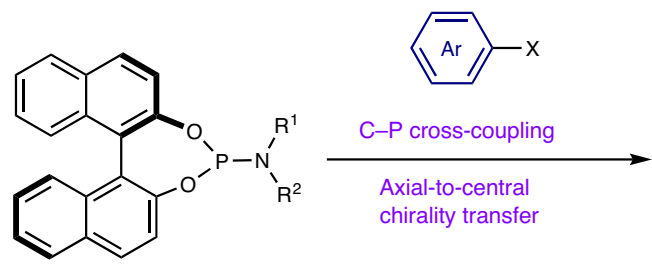

A

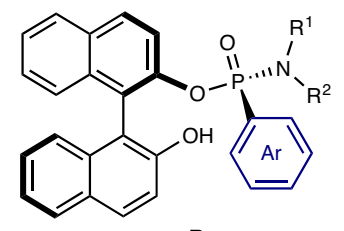

B
An axial-to-central chirality transfer in a C-P coupling event

$\square \mathrm{P}(\mathrm{III})$ as starting material

Easy access to the starting materials

Excellent chemo- and stereo-selectivity

Excellent functional group tolerance

Mechanistic study

Enantiodivergent synthesis of $\mathrm{P}$-chiral phosphines
$(R)-\mathbf{D}$ Leaving group installation

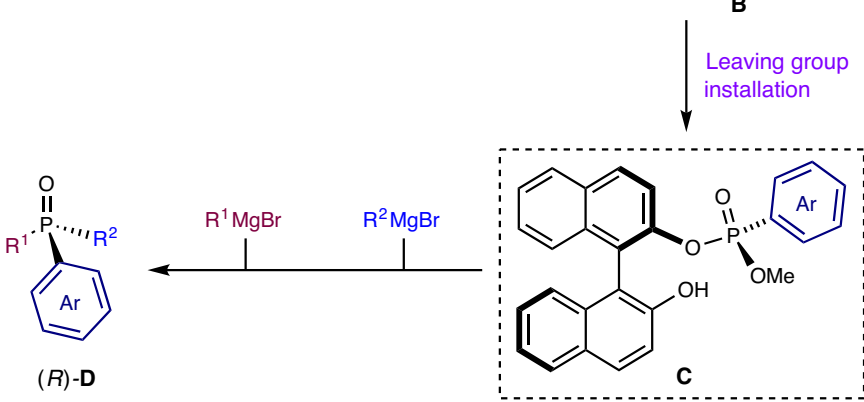

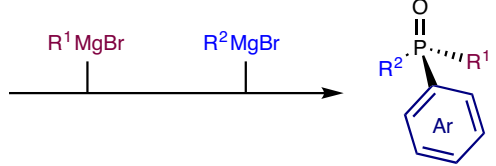

(S)-E

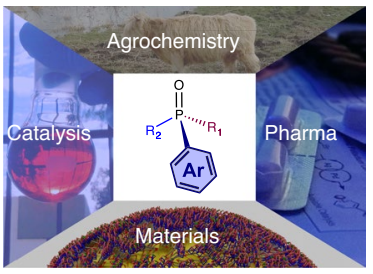

b

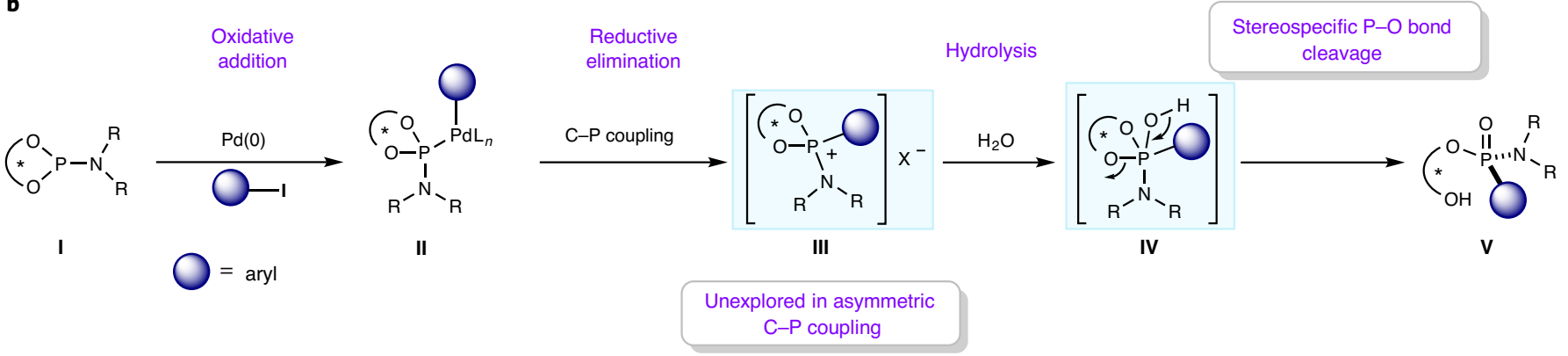

Fig. 1 | Blueprint for the generation for P-stereogenic centres. a, C-P cross-coupling and axial-to-central chirality transfer towards the synthesis of P-chirogenic compounds. b, Proposed reaction mechanism: cross-coupling and hydrolysis of phosphonium salt. L, Ligand.

phosphorus centre and could therefore undergo attack by $\mathrm{H}_{2} \mathrm{O}$ to afford hydroxyphosphorane intermediate IV. Finally, this intermediate is converted into the thermodynamically more stable product $\mathbf{V}$ via a stereospecific cleavage of one of the P-O bonds from BINOL. The stereoselective formation of a P-stereogenic centre in the catalytic P-arylation and the flexibility in the subsequent steps from arylphosphonate $\mathbf{C}$ (Fig. 1a) allows the formation of a variety of P-chiral compounds governed by the sequence of Grignard or organolithium additions.

In this Article, we report the realization of this methodology for the synthesis of a wide range of P-chirogenic phosphinates and phosphine oxides (common precursors to phosphines) via a palladium-catalysed stereoselective $\mathrm{C}-\mathrm{P}$ cross-coupling reaction followed by hydrolysis and subsequent functionalization with Grignard reagents.

\section{Results}

Preliminary studies and optimization. The feasibility of the stereoselective catalytic $\mathrm{P}$-arylation was investigated by the $\mathrm{C}-\mathrm{P}$ coupling of phosphoramidite $(R)$-1a with $p$-iodoanisole in the presence of $\mathrm{Pd}_{2}(\text { dibenzylideneacetone }(\mathrm{dba}))_{3}$ as the catalyst and $\mathrm{Cs}_{2} \mathrm{CO}_{3}$ as the base (Table 1). To our delight, preliminary studies revealed quantitative formation of phosphonamidate $\left(R, S_{\mathrm{p}}\right)$-2aa, with $85 \%$ isolated yield when the reaction was conducted in the presence of $10 \mathrm{~mol} \% \mathrm{Pd}_{2}(\mathrm{dba})_{3}, 3$ equiv. (equivalent) of $p$-iodoanisole and 2 equiv. of $\mathrm{Cs}_{2} \mathrm{CO}_{3}$ at $50^{\circ} \mathrm{C}$ in toluene under a nitrogen atmosphere (Table 1, entry 1. Note: $R$ and $S_{\mathrm{p}}$ indicate configuration of BINOL and phosphorus centre, respectively). This transformation proceeds with near complete chemo- and diastereo-selectivity (98:2 diastereomeric ratio, d.r.), showing no evidence of $\mathrm{P}-\mathrm{N}$ bond cleavage (see Supplementary characterization of C-P coupling products for detailed reaction conditions, experimental details and full characterization of $\left(R, S_{\mathrm{P}}\right)$-2aa). Importantly, lowering the catalyst loading from 10 to $1 \mathrm{~mol} \%$ had a negligible effect on the efficiency of the reaction, as is evident from the excellent yield (92\%) obtained, without compromising stereoselectivity (Table 1, entry 2 ). No conversion was observed without base (Table 1, entry 3 ), while the use of equimolar amounts of aryl iodide did not affect the yield of this transformation (Table 1, entry 4). The use of only 1 equiv. of base led to a decrease in the conversion ( $41 \%$, Table 1 , entry 5$)$, although quantitative conversion was restored by simply running the reaction in more concentrated solution ( $>95 \%$, Table 1 , entry 6$)$. 
Table 1 | Conditions for the C-P cross-coupling

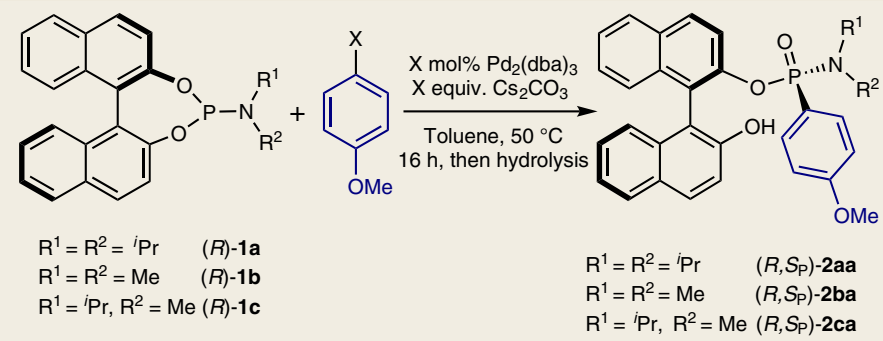

\begin{tabular}{|c|c|c|c|c|c|c|}
\hline Entry & $\mathrm{Pd}_{2}(\mathrm{dba})_{3}(\mathrm{~mol} \%)$ & $\mathrm{Cs}_{2} \mathrm{CO}_{3}$ (equiv.) & ArX (equiv.) & Concentration (M) & $\begin{array}{l}\text { Conversion into }\left(R, S_{\mathrm{p}}\right)-2 \text { aa (yield } \\
(\%))^{f}\end{array}$ & d.r. \\
\hline 1 & 10 & 2 & $3(X=1)$ & 0.05 & $>95(85)$ & $>98: 2$ \\
\hline 2 & 1 & 2 & $3(X=1)$ & 0.05 & $>95(92)$ & $>98: 2$ \\
\hline 3 & 1 & 0 & $3(X=1)$ & 0.05 & $\mathrm{O}$ (only SM) & n.d. \\
\hline 4 & 1 & 2 & $1(X=I)$ & 0.05 & $>95$ (89) & $>98: 2$ \\
\hline 5 & 1 & 1 & $1(X=I)$ & 0.05 & 41 & $>98: 2$ \\
\hline 6 & 1 & 1 & $1(X=I)$ & 0.1 & $>95$ & $>98: 2$ \\
\hline $7^{b}$ & 1 & 1 & $1(X=I)$ & 0.1 & $>95$ & $>98: 2$ \\
\hline $8^{c}$ & 1 & 1 & $1(X=1)$ & 0.1 & 26 & $>98: 2$ \\
\hline $9^{d}$ & 1 & 1 & $1(X=I)$ & 0.1 & $\sim 10$ & n.d. \\
\hline $10^{e}$ & 1 & 1 & $1(\mathrm{X}=\mathrm{Br})$ & 0.1 & $(76)$ & $91: 9$ \\
\hline $11^{e}$ & 1 & 1 & $1(\mathrm{X}=\mathrm{OTf})$ & 0.1 & $(78)$ & $90: 10$ \\
\hline
\end{tabular}

${ }^{a}$ All reactions were performed with $(R)-1 \mathrm{a}(0.12 \mathrm{mmol}), \mathrm{Pd}_{2}(\mathrm{dba})_{3}(10-1 \mathrm{~mol} \%), \operatorname{ArX}\left(1-3\right.$ equiv.), $\mathrm{Cs}_{2} \mathrm{CO}_{3}(1-2$ equiv. $)$ reacted in toluene at $50^{\circ} \mathrm{C}$ for $16 \mathrm{~h}$, conversion and d.r. determined by ${ }^{31} \mathrm{P} \mathrm{NMR}$ of the

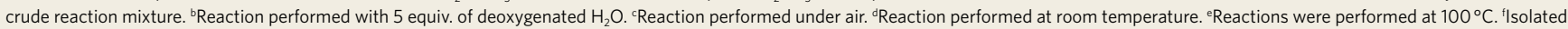
yield. ${ }^{8}$ Reactions performed with $(R)-\mathbf{1 b}, \mathbf{c}(0.3 \mathrm{mmol}), \mathrm{Pd}_{2}(\mathrm{dba})_{3}(1 \mathrm{~mol} \%)$, $\mathrm{Arl}\left(1\right.$ equiv.), $\mathrm{Cs}_{2} \mathrm{CO}_{3}(1$ equiv.). $\mathrm{SM}$, starting material; n.d., not detected.

Remarkably the addition of 5 equiv. of deoxygenated water had no effect and gave $\left(R, S_{\mathrm{P}}\right)$-2aa in high conversion $(>95 \%$, Table 1 , entry 7). By contrast, running the reaction under air led to $26 \%$ conversion to $\left(R, S_{\mathrm{P}}\right)$-2aa with substantial amounts of a by-product $(45 \%)$, resulting from oxidation of phosphoramidite $(R)-\mathbf{1 a}$ (Table 1, entry 8 ) highlighting the oxygen-sensitive nature of this transformation. Further optimization of the reaction conditions and initial scaling up of experiments revealed $70^{\circ} \mathrm{C}$ as the preferred reaction temperature while the use of different bases showed no significant influence on the reaction outcome (see Supplementary Table 1 for further details). We next evaluated the use of other arene electrophilic partners (Table 1, entries 10 and 11). Aryl bromides and triflates, although less reactive, reacted smoothly with phosphoramidite $(R)-\mathbf{1 a}$ at $100^{\circ} \mathrm{C}$ instead of $70^{\circ} \mathrm{C}$, forming the corresponding $\mathrm{C}-\mathrm{P}$ coupling product $\left(R, S_{\mathrm{P}}\right)$-2aa in good yields (76-78\%). The slightly diminished diastereomeric ratios observed in both cases (91:9 and 90:10) could be attributed to the required increased reaction temperature, as the reaction of $(R)-1$ a with $p$-iodoanisole at $100^{\circ} \mathrm{C}$ provided $\left(R, S_{\mathrm{P}}\right)$-2aa in a lower d.r. (93:7) compared to the reaction conducted at $70{ }^{\circ} \mathrm{C}$ (>98:2 d.r.). Nevertheless, an effect of the counterion on the lower diastereomeric ratios observed cannot be excluded. Studying the influence of the steric effect of the amine moiety at the phosphoramidite, an apparent key parameter with respect to chemo- and stereo-selectivity, phosphoramidites $(R)-\mathbf{1 b}$ and $(R)$-1c, with distinct sizes of alkyl groups at the nitrogen $\left(\mathrm{Me}\right.$ and $\left.{ }^{i} \mathrm{Pr}\right)$ were used. MonoPhos $((R)-\mathbf{1 b})$ reacted smoothly at $70^{\circ} \mathrm{C}$ with $p$-iodoanisole, although due to competing $\mathrm{P}-\mathrm{O} / \mathrm{P}-\mathrm{N}$ bond cleavage, the by-product that results from the elimination of the amine fragment was observed together with $55 \%$ of the desired product $\left(R, S_{\mathrm{P}}\right)-\mathbf{2 b a}$. By contrast, phosphoramidite $(R)$-1c containing an unsymmetrical amine afforded $\left(R, S_{\mathrm{p}}\right)-\mathbf{2 c a}$ in $78 \%$ yield and a slightly diminished d.r. of $85: 15$, with no signs of $\mathrm{P}-\mathrm{N}$ cleavage (see Supplementary Note 1 for an explanation of the lower d.r. observed for $(R)-\mathbf{1 c}$ ).

Scope of aryl iodide and functional group tolerance. Given the superior results obtained using $(R)-\mathbf{1 a}$, this phosphoramidate was selected to evaluate the scope of aryl iodides in the transformation (Fig. 2). However, in a few cases (R)-1b was used because of its improved performance especially with sterically hindered aryl iodides. Aryl iodides substituted with a range of electron-donating and electron-withdrawing groups reacted smoothly to furnish the corresponding P-chiral phosphonoamidates with, in most cases, excellent yields and diastereoselectivity. Both phosphoramidites $(R)$-1a and $(R)-\mathbf{1 b}$ reacted with phenyl iodide in a completely stereoselective C-P coupling (>98:2 d.r) to afford $\left(R, S_{\mathrm{P}}\right)-\mathbf{2 a b}$ and $\left(R, S_{\mathrm{P}}\right)$ $\mathbf{2 b b}$, respectively. Aryl iodides with electron-donating groups at different positions at the aromatic ring (ortho, meta, para) readily 


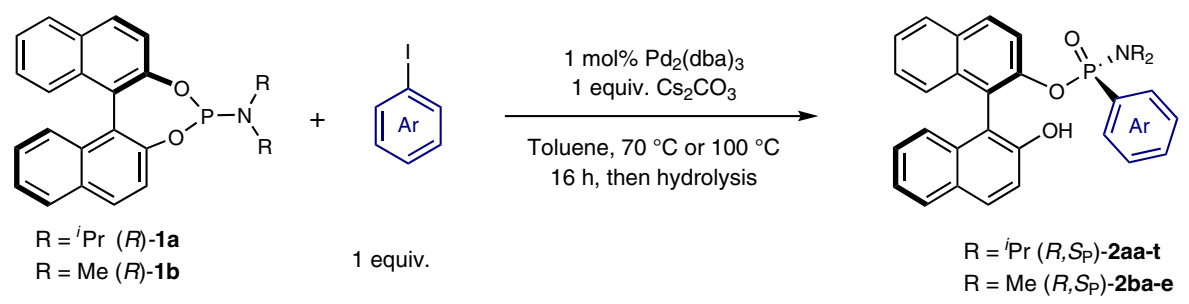

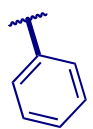

$\left(R, S_{\mathrm{P}}\right)-\mathbf{2 a b}, 81 \%,>98: 2$ d.r. ${ }^{[\mathrm{b}]}$ (R,S $)$-2bb, 55\%, >98:2 d.r.<smiles>COc1cccc(C(C)(C)C)c1</smiles>

(R, $\left.S_{\mathrm{P}}\right)-2$ af, $82 \%$, >98:2 d.r.<smiles>Cc1ccc(Cl)cc1</smiles>

$\left(R, S_{\mathrm{P}}\right)-\mathbf{2 a j}, 53 \%,>98: 2$ d.r.<smiles>CC(=O)c1ccc(C)cc1</smiles>

(R,Sp)-2an, 54\%, 87:13 d.r. ${ }^{[a]}$<smiles>CCc1ccc2ncccc2c1</smiles>

(R,S $)$-2as, $57 \%$, 98:2 d.r.<smiles>Cc1ccc(C)cc1</smiles>

$\left(R, S_{\mathrm{P}}\right)-2$ ac, $92 \%,>98: 2$ d.r.<smiles>COc1ccccc1C</smiles>

$\left(R, S_{\mathrm{P}}\right)-\mathbf{2 b c}, 52 \%,>98: 2$ d.r.

(R,S $)$-2ag, $86 \%, 98: 2$ d.r.<smiles>Cc1ccc(O)cc1</smiles>

$\left(R, S_{\mathrm{P}}\right)-\mathbf{2 a k}, 60 \%,>98: 2$ d.r.

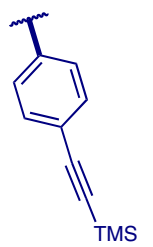

$\left(R, S_{\mathrm{P}}\right)-\mathbf{2 a o}, 35 \%, 97: 3$ d.r.

(R,SP)-2ap, $65 \%$, >98:2 d.r. ${ }^{[a]}$<smiles>Cc1cc(C)cc(C(C)(C)C)c1</smiles>

(R,S $)$-2ae, 90\%, 97:3 d.r.<smiles>CCc1cccc2ccccc12</smiles>

$\left(R, S_{\mathrm{P}}\right)-2 \mathrm{ah},<5 \%$ conversion $\left(R, S_{\mathrm{P}}\right)-2 \mathrm{bd}, 66 \%$, $>98: 2$ d.r.<smiles>Cc1ccc(N)cc1</smiles>

(R, $\left.S_{\mathrm{P}}\right)$-2am, $71 \%, 95: 5$ d.r.<smiles>CCc1ccc(C=O)cc1</smiles>

(R, $\left.S_{\mathrm{P}}\right)$-2aq, $<5 \%$ conversion (R,SP)-2be, $23 \%$, >98:2 d.r. ${ }^{[\mathrm{a}][\mathrm{c}]}$

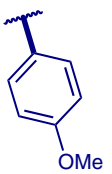

(R, $\left.S_{\mathrm{P}}\right)-2$ aa, $90 \%,>98: 2$ d.r.<smiles>Cc1ccc(F)cc1</smiles>

(R,S $)$-2ai, $48 \%$, >98:2 d.r. $75 \%, 94: 6$ d.r. ${ }^{[a]}$
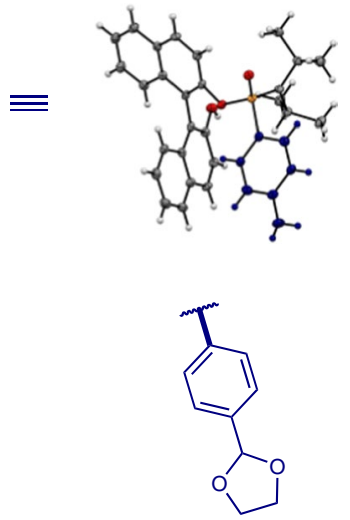

(R,S $)$-2ar, 50\%, 95:5 d.r. $76 \%, 94: 6$ d.r. ${ }^{[a]}$<smiles>Cc1ccsc1</smiles>

(R, $\left.S_{\mathrm{P}}\right)$-2at, $84 \%, 86: 14$ d.r.

Fig. 2 | Scope for the synthesis of P-chiral phosphonamidates via a C-P coupling reaction. All reactions were performed with 0.3 mmol of phosphoramidite $(R)-1 \mathbf{a}$ or $(R)-1 \mathbf{b}, \mathrm{Pd}_{2}(\mathrm{dba})_{3}(1 \mathrm{~mol} \%)$, Arl (1 equiv.), $\mathrm{Cs}_{2} \mathrm{CO}_{3}$ (1 equiv.) in toluene at $70^{\circ} \mathrm{C}$ for $16 \mathrm{~h}$. Yields are reported as isolated yield; d.r. values were determined using ${ }^{31} \mathrm{P}$ NMR of the crude reaction mixture. [a] Reaction at $100^{\circ} \mathrm{C}$. [b] Reaction was also performed on $5 \mathrm{~g}$ scale ( $83 \%$ yield). [c] NMR yield. See Supplementary characterization of C-P coupling products for detailed reaction conditions.

participated in the reaction to give $\left(R, S_{\mathrm{p}}\right)-\mathbf{2 a c}-\mathbf{2 a f}$ and $\left(R, S_{\mathrm{p}}\right)-\mathbf{2 b c}$ in $52-92 \%$ yield, again with excellent diastereoselectivity $(>97: 3$ d.r.). A notable difference in reactivity was observed between 1- and 2-iodonaphthalene. While phosphoramidite $(R)$-1a reacted readily with 2-iodonaphthalene to afford $\left(R, S_{\mathrm{p}}\right)$-2ag in $86 \%$ isolated yield, no conversion was observed with 1-iodonaphthalene, which is attributed to increased steric hindrance. The decreased reactivity observed for more hindered aryl coupling partners can be easily compensated by switching to phosphoramidite $(R)-\mathbf{1 b}$ instead of $(R)-\mathbf{1 a}$, as observed in the formation of $\left(R, S_{\mathrm{P}}\right)-\mathbf{2} \mathbf{b d}$. In general, aryl iodides containing electron-withdrawing groups reacted more slowly under the standard reaction condition $\left(70^{\circ} \mathrm{C}\right)$, but increasing the reaction temperature to $100^{\circ} \mathrm{C}$ significantly enhanced the product yield, that is, $\left(R, S_{\mathrm{P}}\right)$-2ai and $\left(R, S_{\mathrm{P}}\right)$-2ap. Aryl iodides substituted with various halogens $(-\mathrm{F},-\mathrm{Cl},-\mathrm{Br})$ were also tolerated, providing the corresponding products $\left(\left(R, S_{\mathrm{P}}\right)-\mathbf{2 a i}-\mathbf{2 a k}\right)$ in $53-75 \%$ yield and high diastereoselectivity ( $>94: 6$ d.r.). It is remarkable that in the presence of both $\mathrm{Cs} p^{2}-\mathrm{Br}$ and $\mathrm{Cs} p^{2}-\mathrm{I}$, only the aryl iodide participates in the $\mathrm{C}-\mathrm{P}$ coupling event, leaving the aryl bromide $\left(\left(R, S_{\mathrm{P}}\right)\right.$-2ak $)$ intact. This chemoselectivity provides an additional and versatile means for subsequent functionalizations of the chiral product. To gain more insight into the compatibility of various functional groups with the 
a<smiles>CC(C)N(C(C)C)p1oc2ccc3ccccc3c2c2c(ccc3ccccc32)o1</smiles>

(R)-1a
$5 \mathrm{~mol} \% \mathrm{Pd}_{2}(\mathrm{dba})_{3}$

1 equiv. KOTf

1 equiv. $\mathrm{Phl}$

Toluene, $70^{\circ} \mathrm{C}$

$16 \mathrm{~h}$, hydrolysis

$71 \%$ conversion<smiles>CCCNP(=O)(Oc1ccc2ccccc2c1-c1c(O)ccc2ccccc12)[Pb](=O)c1ccccc1</smiles>

$\left(R, S_{\mathrm{P}}\right)-\mathbf{2 a b}$<smiles></smiles>

[( $\left.R, S_{\mathrm{P}}\right)$ - 2ab-Int $] \mathrm{OTf}$

(39:61 ratio) $\quad{ }^{31} \mathrm{P}$ NMR $55 \mathrm{ppm}$

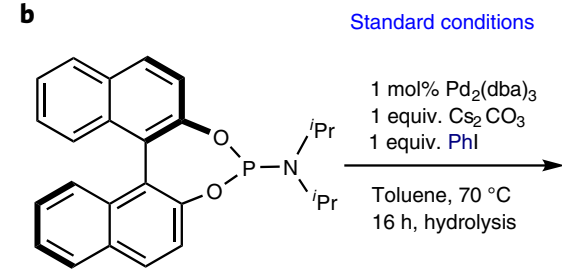

(R)-1a

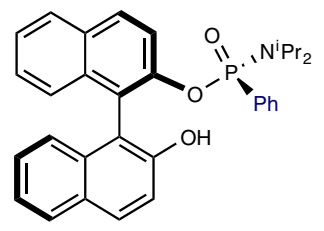

$\left(R, S_{\mathrm{P}}\right)-\mathbf{2 a b}, 85 \%,>98: 2$ d.r.

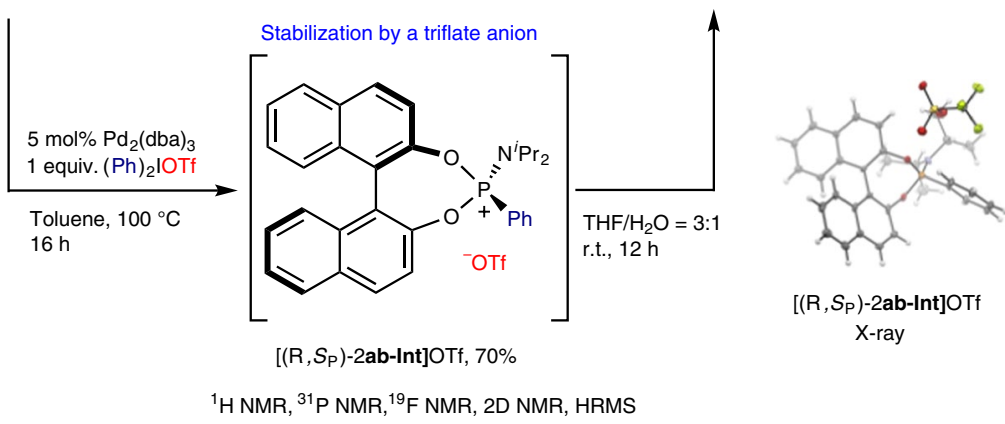

Fig. 3 | Investigation of the possible phosphonium intermediate. a, Transformation of phosphoramidite ( $R$ )-1a to the phosphonium intermediate $\left[\left(R, S_{p}\right)\right.$-2ab-Int $]$ OTf in the presence of KOTf as an additive. $\mathbf{b}$, Isolation and characterization of $\left[\left(R, S_{p}\right)-2\right.$ ab-Int $]$ OTf, followed by transformation to $\left(R, S_{\mathrm{p}}\right)-2 \mathrm{ab}$ by hydrolysis.

conditions for this stereoselective C-P cross-coupling reaction, aryl iodides bearing reactive functional groups were examined. Besides, halides, aniline, phenol, ester $\left(-\mathrm{CO}_{2} \mathrm{Et}\right)$, ketone $(-\mathrm{COMe})$ and alkyne were tolerated, providing products $\left(R, S_{\mathrm{P}}\right)$-2al-2ar and $\left(R, S_{\mathrm{P}}\right)$-2 $\mathbf{2 b e}$ with good yields and excellent diastereoselectivity ( $>98: 2-95: 5$ d.r.) (only in the case of ketone $\left(R, S_{\mathrm{p}}\right)$-2an a slightly diminished d.r. of 87:13 was found). Remarkably, an unprotected aldehyde can take part in our C-P coupling event providing the product $\left(R, S_{\mathrm{P}}\right)-\mathbf{2 b e}$ (full conversion of $(R)-\mathbf{1 b}$ and $23 \%$ yield based on NMR analysis, $>98: 2$ d.r.). although it was found to be extremely unstable during the purification step (see Supplementary characterization of $\mathrm{C}-\mathrm{P}$ coupling products for detailed reaction conditions). However, using a dioxolane-substituted aryl iodide, protected aldehyde $\left(R, S_{\mathrm{P}}\right)$-2ar was isolated in $76 \%$ yield with excellent diastereoselectivity. Finally, heteroaromatic iodides, such as 6-iodoquinoline and 3 -iodothiophene, were successfully converted into the corresponding products $\left(R, S_{\mathrm{P}}\right)$-2as and $\left(R, S_{\mathrm{P}}\right)$-2at. To evaluate the scalability of this methodology, the transformation was performed on a multigram scale $(5 \mathrm{~g})$ and after easy purification $\left(R, S_{\mathrm{P}}\right)-\mathbf{2 a b}(83 \%,>98: 2$ d.r.) was obtained with excellent chemo- and stereo-selectivity. The d.r. values were determined by NMR analysis and the absolute configurations of all products were based on the known configuration of the BINOL moiety in the phosphoramidite and X-ray crystallographic analysis of $\left(R, S_{\mathrm{P}}\right)$-2am.

Preliminary mechanistic studies. In order to obtain detailed insight into the highly selective aryl coupling leading to the formation of P-chirogenic product $\left(R, S_{\mathrm{P}}\right)-\mathbf{2} \mathbf{a b}$, we focused on the key phosphonium intermediate (III, Fig. 1b). Under standard reaction conditions we were unable to observe any other species except the hydrolysed products (as shown in Fig. 2) either before or after the aqueous workup, suggesting that the anticipated phosphonium intermediate formed in the Pd-catalysed coupling with phenyl iodide (where $\mathrm{I}^{-}$is the counter anion) is highly susceptible to hydrolysis by trace amounts of water. Hence, we performed a reaction in the presence of potassium triflate (KOTf) as an additive in order to stabilize the phosphonium salt formed in situ by exchanging the $\mathrm{I}^{-}$ with an $\mathrm{OTf}^{-}$anion (see Supplementary Note 2 for an explanation of the stability of the phosphonium triflates). Indeed, full conversion of the phosphoramidite $(R)$-1a was observed towards the formation of a new species at $\delta=55.4 \mathrm{ppm}$ in ${ }^{31} \mathrm{P}$ NMR (ref. ${ }^{53}$ ) suggesting the formation of $\left[\left(R, S_{\mathrm{p}}\right)\right.$-2ab-Int $] \mathrm{OTf}$ (Fig. 3a), alongside substantial amounts of hydrolysed product $\left(R, S_{\mathrm{P}}\right)$-2ab (Fig. 3a). The observation of the hydrolysed product $\left(R, S_{\mathrm{P}}\right)-\mathbf{2 a b}$ indicates that anion exchange and hydrolysis are competing reactions (similar results were observed using $\mathrm{KPF}_{6}$, see Supplementary Fig. 3). In parallel experiments, the independent synthesis of the postulated intermediate phosphonium salt $\left[\left(R, S_{\mathrm{P}}\right)\right.$-2ab-Int $]$ OTf was performed using diphenyliodonium triflate ${ }^{47}$ instead of phenyl iodide as the electrophile in order to stabilize the phosphonium salt without the need of an anion exchange reaction (Fig. 3b). Full conversion of $(R)-\mathbf{1 a}$ was observed with $70 \%$ isolated yield to the $\left[\left(R, S_{\mathrm{P}}\right)\right.$-2ab-Int $] \mathrm{OTf}$ and the structure of the phosphonium triflate $\left[\left(R, S_{\mathrm{P}}\right)-\mathbf{2 a b}-\mathbf{I n t}\right]$ OTf was unequivocally established using NMR spectroscopy, high-resolution mass spectrometry (HRMS) and single crystal $\mathrm{X}$-ray analysis (see Supplementary Fig. 19 for details). The observed 
Table 2 | Stereospecific nucleophilic substitution of $\left(R, S_{\mathrm{p}}\right)-3$ and $\left(R, S_{\mathrm{p}}\right)-4 \mathrm{a}-\mathrm{c}^{\mathrm{a}}$

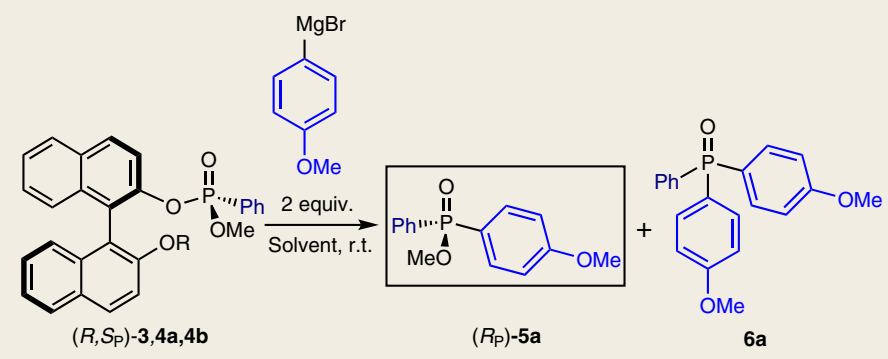

\begin{tabular}{|c|c|c|c|c|c|c|c|}
\hline Entry & $\mathbf{R}$ & Solvent & Time & Concentration (M) & Conversion ${ }^{\mathrm{b}}$ & $5 a: 6 a^{b}$ & e.r. ${ }^{c}(y i e l d(\%))$ \\
\hline 1 & $\operatorname{Me}(4 a)$ & THF & $3 \mathrm{~h}$ & 0.1 & Full & $92: 8$ & $86: 14(87)$ \\
\hline 2 & $H(3)$ & THF & $3 \mathrm{~h}$ & 0.1 & $13 \%$ & $100: 0$ & $81: 19$ \\
\hline 4 & TBDMS (4b) & $\mathrm{PhMe}$ & $3 \mathrm{~h}$ & 0.1 & $80 \%$ & $97: 3$ & $88: 12$ \\
\hline 5 & TBDMS (4b) & Dioxane & $3 \mathrm{~h}$ & 0.1 & Full & $68: 32$ & $91: 9$ \\
\hline 8 & TBDPS (4c) & Dioxane/ $\mathrm{Et}_{2} \mathrm{O}$ & $2 \mathrm{~h}$ & 0.05 & $95 \%$ & $82: 18$ & $96: 4(73)$ \\
\hline
\end{tabular}

${ }^{a}$ All reactions were performed with $0.06 \mathrm{mmol}$ of the corresponding phosphonate. ${ }^{\mathrm{b}} \mathrm{C}$ onversion was monitored using ${ }^{31} \mathrm{P}$ NMR. ${ }^{\mathrm{C}}$ The e.r. value was determined by chiral stationary phase HPLC.

chirality at phosphorus indicates that the Pd-catalysed C-P coupling reaction proceeds with excellent stereocontrol, providing the homochiral P-chirogenic intermediate which, upon hydrolysis, provides product $\left(R, S_{\mathrm{P}}\right)$-2ab. This finding supports the hypothesis that the quaternary phosphonium salt $\left[\left(R, S_{\mathrm{P}}\right)\right.$-2ab-Int $] \mathrm{X}(\mathrm{X}=\mathrm{I}, \mathrm{OTf})$ is the key intermediate during the Pd-catalysed arylation and that both the aryl coupling and water addition steps (the latter cleaving exclusively one of the two phenolate $\mathrm{P}-\mathrm{O}$ bonds) occur with excellent stereocontrol at the phosphorus centre. This study provides the asymmetric synthesis of a chiral phosphonium salt starting from an achiral phosphorus compound.

Application. With a robust method for the stereoselective synthesis of P-chiral phosphonamidates in hand, the formation of P-chiral phosphonates and phosphine oxides was investigated (Fig. 4). Facing the challenge of sequential replacement of amine and naphthol moieties in $\left(R, S_{\mathrm{p}}\right)$-2ab using aryl and alkyl organometallic reagents retaining full stereocontrol at the P-chirogenic centre, initially organolithium substitution reactions were examined. Surprisingly, the use of an organolithium reagent $\left({ }^{n} \mathrm{BuLi}\right.$ or $\left.\mathrm{PhLi}\right)$ at $-78^{\circ} \mathrm{C}$ with $\left(R, S_{\mathrm{P}}\right)-\mathbf{2 a b}$ led to the stereoselective formation of phosphinic amide $\left(R, S_{\mathrm{p}}\right)$-2ab-1 in almost quantitative yield as a result of an anionic phospho-Fries rearrangement ${ }^{54}$ (see Supplementary Fig. 4 for details). Phosphinic amide $\left(R, S_{\mathrm{P}}\right)$-2ab-1 (Supplementary Fig. 4) featuring axial chirality and a P-stereogenic centre offers an attractive scaffold for $\mathrm{P}, \mathrm{O}$-donor ligands, particularly useful in asymmetric organocatalysis ${ }^{55}$. In order to facilitate $\mathrm{P}-\mathrm{C}$ bond formation, the amine moieties in $\left(R, S_{\mathrm{p}}\right)-\mathbf{2} \mathbf{a b}$ and $\left(R, S_{\mathrm{p}}\right)$-2 $\mathbf{b} \mathbf{b}$ were chemoselectively exchanged for a methoxy group by an acid-catalysed methanolysis reaction, affording phosphonate $\left(R, S_{\mathrm{P}}\right)-3$ in 80 and $98 \%$ yield, respectively (Fig. $4 \mathrm{a})$. This reaction proceeded with complete inversion of configuration at the phosphorus stereocentre, as confirmed by X-ray crystallographic analysis of $\left(R, S_{\mathrm{P}}\right)$-3 (see Supplementary Fig. 21 for details). Homochiral phosphonate $\left(R, S_{\mathrm{P}}\right)$ 3 provides an excellent starting point for the preparation of a variety of P-chiral compounds (Fig. 1a). However, some practical challenges need to be taken into consideration. First, the chiral auxiliary BINOL needs to be replaced without compromising the chirality at phosphorus. Second, deprotonation of the phenolic hydroxyl group with an organometallic reagent might result in the formation of a pentavalent hydroxyphosphorane intermediate, leading to a decrease in reactivity towards substitution at the phosphorus centre. Third, sequential substitution at phosphonates has been found to be challenging due to the preferred formation of double addition products in most cases ${ }^{56}$. In order to avoid the formation of a hydroxyphosphorane intermediate, the hydroxyl group in $\left(R, S_{\mathrm{P}}\right)-3$ was equipped with various protecting groups to form $\left(R, S_{\mathrm{p}}\right)-\mathbf{4 a}-\mathbf{c}$ maintaining the stereochemical integrity (Fig. $4 \mathrm{~b}$, as confirmed by X-ray analysis of $\left(R, S_{\mathrm{p}}\right)-\mathbf{4 c}$, see also Supplementary Fig. 22 for crystal data). Initial treatment of a solution of methyl-protected compound $\left(R, S_{\mathrm{P}}\right) \mathbf{- 4 a}$ in THF at room temperature (r.t.) in the presence of 2 equiv. of $p$-methoxyphenylmagnesium bromide resulted in substitution of the BINOL unit providing mono-addition product diarylphosphonate $\left(R_{\mathrm{P}}\right)$-5a with full conversion (isolated yield $87 \%$ ), excellent chemoselectivity and 86:14 enantiomeric ratio (e.r., Table 2, entry 1). The diminished stereospecificity is most likely to be due to a partial epimerization at the P-stereogenic centre, induced by the metalated BINOL leaving group entering a nucleophilic substitution with unreacted starting phosphonate $\left(R, S_{\mathrm{P}}\right)-\mathbf{4 a}$ (ref. $\left.{ }^{57}\right)$. To further confirm this hypothesis, we compared the reactions with $p$-anisylmagnesium bromide in THF of unprotected phosphonate $\left(R, S_{\mathrm{p}}\right)-\mathbf{3}$ and bulky silicon-protected phosphonate $\left(R, S_{\mathrm{P}}\right)$-4b. Unprotected phosphonate $\left(R, S_{\mathrm{P}}\right)-\mathbf{3}$ reacted slowly showing only $13 \%$ conversion towards $\left(R_{\mathrm{P}}\right)-5 \mathrm{a}$ with a decrease in enantiomeric ratio (81:19 e.r., Table 2, entry 2$)$. On the contrary, the same reaction with phosphonates $\left(R, S_{\mathrm{p}}\right)-\mathbf{4 b}$ and $\left(R, S_{\mathrm{p}}\right)-\mathbf{4} \mathbf{c}$, featuring a tert-butyldimethylsilyl (TBDMS) or tert-butyldiphenylsilyl (TBDPS) protecting group, resulted in higher enantioselectivity (88:12-96:4 e.r., respectively, Table 2, entries 3-8). The increased steric hindrance of the leaving group due to the silicon protecting group (TBDMS or TBDPS) compared to the [1,1'-binaphthalene]$2,2^{\prime}$-bis(olate), leads to the suppression of the epimerization at the phosphorus stereocentre. Exploring different solvents and protecting groups revealed that double addition could be largely suppressed and high stereocontrol was achieved using a solvent mixture of 1,4-dioxane/diethyl ether (2:1); the mono-addition product 
<smiles>[R]N([R])P(=O)(Oc1ccc2ccccc2c1-c1c(O)ccc2ccccc12)P(C)O[Na]</smiles>

$\left(R, S_{\mathrm{P}}\right)-\mathbf{2 a b},>98: 2 \mathrm{~d} . \mathrm{r}$ $\left(R, S_{\mathrm{P}}\right)-\mathbf{2 b b},>98: 2$ d.r.

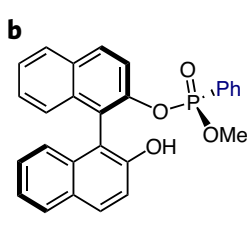

$\left(R, S_{\mathrm{p}}\right)-3,>98: 2$ d.r

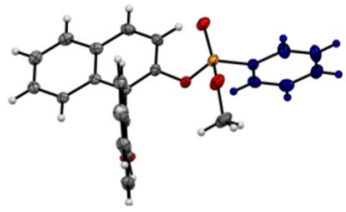

X-ray of $\left(R, S_{\mathrm{P}}\right)-\mathbf{3}$

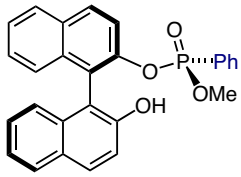

$\left(R, S_{\mathrm{P}}\right)-3$

$\mathrm{R}={ }^{i} \operatorname{Pr}, 80 \%,>98: 2$ d.r., $48 \mathrm{~h}$ $\mathrm{R}=\mathrm{Me}, 98 \%,>98: 2$ d.r., $1 \mathrm{~h}$

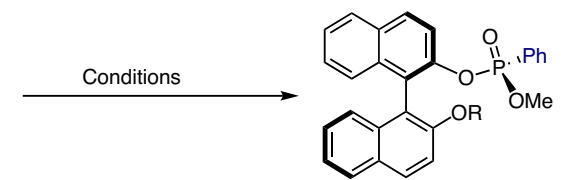

$\mathrm{R}=\mathrm{Me} \quad\left(R, S_{\mathrm{P}}\right)-\mathbf{4 a}, 98 \%,>98: 2$ d.r. $^{[\mathrm{a}]}$ $\mathrm{R}=\mathrm{TBDMS}\left(R, S_{\mathrm{P}}\right)-4 \mathrm{~b}, 93 \%,>98: 2$ d.r. ${ }^{[\mathrm{b}}$ $\mathrm{R}=\operatorname{TBDPS}\left(R, S_{\mathrm{P}}\right)-\mathbf{4 c}, 84 \%, 98: 2$ d.r. $^{[\mathrm{c}]}$

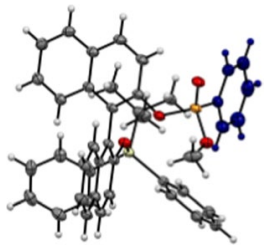

X-ray of $\left(R, S_{\mathrm{P}}\right)-4 \mathrm{c}$
Fig. 4 | Synthetic application of phosphonamidate $\left(R_{r} S_{\mathrm{p}}\right)$-2ab.

$\mathbf{a}$, Installation of methoxy leaving group. $\mathbf{b}$, Protection of phenolic hydroxyl group with various protecting groups. [a] $\left(R, S_{\mathrm{p}}\right)-\mathbf{3}$ (1 equiv.), Mel (4 equiv.) and $\mathrm{K}_{2} \mathrm{CO}_{3}$ (4 equiv.) stirred overnight at r.t. [b] $\left(R, \mathrm{~S}_{\mathrm{P}}\right)-3$ (1 equiv.), $\mathrm{Et}_{3} \mathrm{~N}$ (2 equiv.), tert-butyldimethylsilyl chloride (TBDMSCI) (2 equiv.) stirred overnight at r.t. [c] $\left(R, S_{\mathrm{p}}\right)-3$ (1 equiv.), 4-dimethylaminopyridine (DMAP) (2 equiv.), tert-butylchlorodiphenyl silane (TBDPSCI) (2 equiv.), $35^{\circ} \mathrm{C}$ for $6 \mathrm{~h}$.

phosphinate $\left(R_{\mathrm{P}}\right)$-5a was favoured while retaining excellent enantioselectivity (96:4 e.r., Table 2 , entry 8 ). The addition proceeded as expected with inversion of configuration at the phosphorus centre, as confirmed by the single crystal X-ray analysis of $\left(R_{\mathrm{p}}\right)-\mathbf{5 a}$ (Fig. 5a, see also Supplementary Fig. 23 for more details). Moreover, BINOL could be recovered from the reaction mixture in high yield with total retention of its enantiopurity (see Supplementary additional experiments for details). Having established the optimized reaction conditions for the preparation of phosphinates from the phosphonamidates obtained through our Pd-catalysed asymmetric arylation methodology, a series of Grignard reagents was used for the synthesis of various P-chiral phosphinates (Fig. 5a). Both $p$-tolyl- and $p$-dimethylaniline-magnesium bromides reacted readily to afford $\left(R_{\mathrm{P}}\right)-\mathbf{5} \mathbf{b}$ and $\left(R_{\mathrm{P}}\right)-\mathbf{5} \mathbf{c}$, respectively, in good yields, with excellent enantiomeric purities (95:5 and $96: 4$ e.r.). Additionally, treatment of $\left(R, S_{\mathrm{P}}\right)-4 \mathrm{c}$ with the hindered 2-methoxyphenylmagnesium bromide successfully delivered the corresponding phosphinate with only slightly lower enantiopurity (92:8 e.r.). 2,4-Dimethoxyphenylmagnesium bromide reacted much faster compared to mono-substituted aryl Grignard reagents $(20 \mathrm{~min}$ for $\left(R_{\mathrm{P}}\right)-5 \mathbf{e}$ versus $2 \mathrm{~h}$ for $\left.\left(R_{\mathrm{p}}\right)-5 \mathbf{a}\right)$, providing $\left(R_{\mathrm{p}}\right)-5 \mathbf{e}$ with excellent yield and stereoselectivity. It should be noted that the first displacement reaction with organolithium reagents $(\mathrm{MeLi}, \mathrm{PhLi})$ instead of organomagnesium reagents resulted mainly in the formation of double displacement products (see Supplementary Limitations of the reported method). To obtain the final target homochiral phosphine oxides by stereospecific substitution of the methoxy group in $\left(R_{\mathrm{p}}\right)-5 \mathbf{a}$, a second displacement reaction, using both Grignard and organolithium reagents, was performed (Fig. 5b).

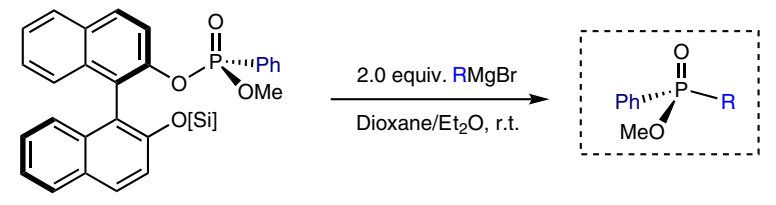

$[\mathrm{Si}]=\mathrm{SiPh}_{2}{ }^{t} \mathrm{Bu}$

$\left(R, S_{\mathrm{P}}\right)-4 \mathrm{c}, 98: 2$ d.r.

$\left(R_{\mathrm{P}}\right)-5 \mathrm{a}-\mathrm{e}$
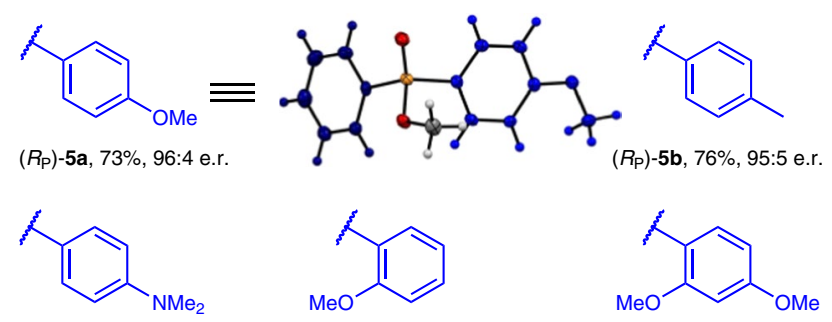

$\left(R_{\mathrm{P}}\right)-\mathbf{5 c}, 76 \%, 96: 4$ e.r.

$\left(R_{\mathrm{P}}\right)-5 \mathrm{~d}, 68 \%, 92: 8$ e.r.

$\left(R_{\mathrm{P}}\right)-5 \mathrm{e}, 86 \%, 93: 7$ e.r.

b

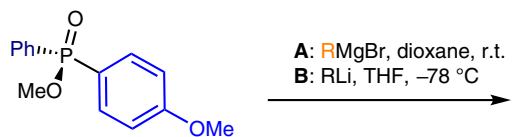

$\left(R_{\mathrm{P}}\right)-5 \mathrm{a}, 96: 4$ e.r

Conditions A

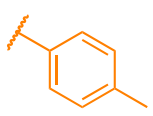

$\left(S_{\mathrm{P}}\right)-7 \mathrm{aa}, 82 \%, 95: 5$ e.r.

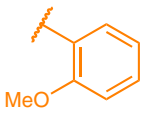

$\left(S_{\mathrm{P}}\right)-7 \mathrm{ab}, 90 \%, 95: 5$ e.r.

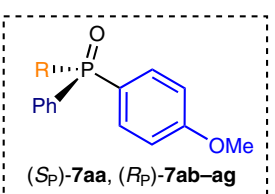

$\left(S_{\mathrm{P}}\right)-7 \mathrm{aa},\left(R_{\mathrm{P}}\right)-7 \mathrm{ab}-\mathrm{ag}$

$\left(S_{\mathrm{P}}\right)-7 \mathrm{ac}, 87 \%, 95: 5$ e.r.

$\left(R_{\mathrm{P}}\right)-7$ ad, $85 \%, 96: 4$ e.r.

$\left(R_{\mathrm{P}}\right)-7 \mathrm{ae}, 98 \%, 95: 5$ e.r.

Conditions B

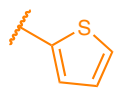

$\left(R_{\mathrm{P}}\right)-7$ af, $75 \%, 96: 4$ e.r.
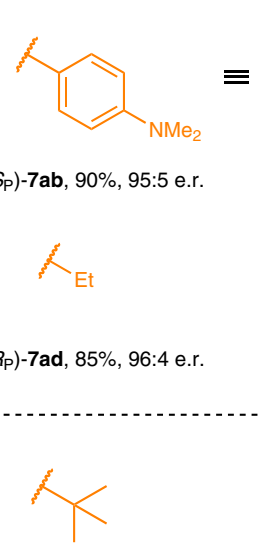

$\left(R_{\mathrm{P}}\right)-7$ ag, $82 \%, 94: 6$ e.r.
Fig. 5 | Stereospecific nucleophilic substitutions of P-chiral compounds. $\mathbf{a}$, Preparation of enantioenriched phosphinates. $\mathbf{b}$, Preparation of enantioenriched phosphine oxides. The e.r. value was determined by chiral stationary phase HPLC. See Supplementary preparation of phosphinates and Supplementary preparation of phosphine oxides for detailed reaction conditions.

The formation of P-stereogenic tertiary phosphine oxides (TPOs) was straightforward upon treatment of $\left(R_{\mathrm{P}}\right)-\mathbf{5 a}$ with Grignard reagents in 1,4-dioxane. It is interesting to note that, on applying $p$-tolyl, $p$-dimethylaniline and $o$-methoxyphenyl Grignard reagents, highly selective formation of the corresponding triarylphosphine oxides $\left(S_{\mathrm{P}}\right)-7 \mathbf{a a},\left(S_{\mathrm{P}}\right)-7 \mathbf{a b}$ and $\left(R_{\mathrm{P}}\right)-7 \mathbf{a c}$ featuring three distinct aryl moieties is seen. The sequence of introduction of the different aryl moieties is entirely dependent on the nature of the aryl iodide and aryl Grignard reagents used in the sequential steps from 1a to $7 \mathbf{a}$ (Figs. 2-5). Alkyl-substituted phosphine oxides $\left(R_{\mathrm{P}}\right)$-7ad and $\left(R_{\mathrm{P}}\right)$ 7ae were also obtained with excellent yields and enantioselectivities (85-98\%, 95:5-96:4 e.r.) when alkylmagnesium bromide reagents were used. Gratifyingly, in the final C-P bond formation, 


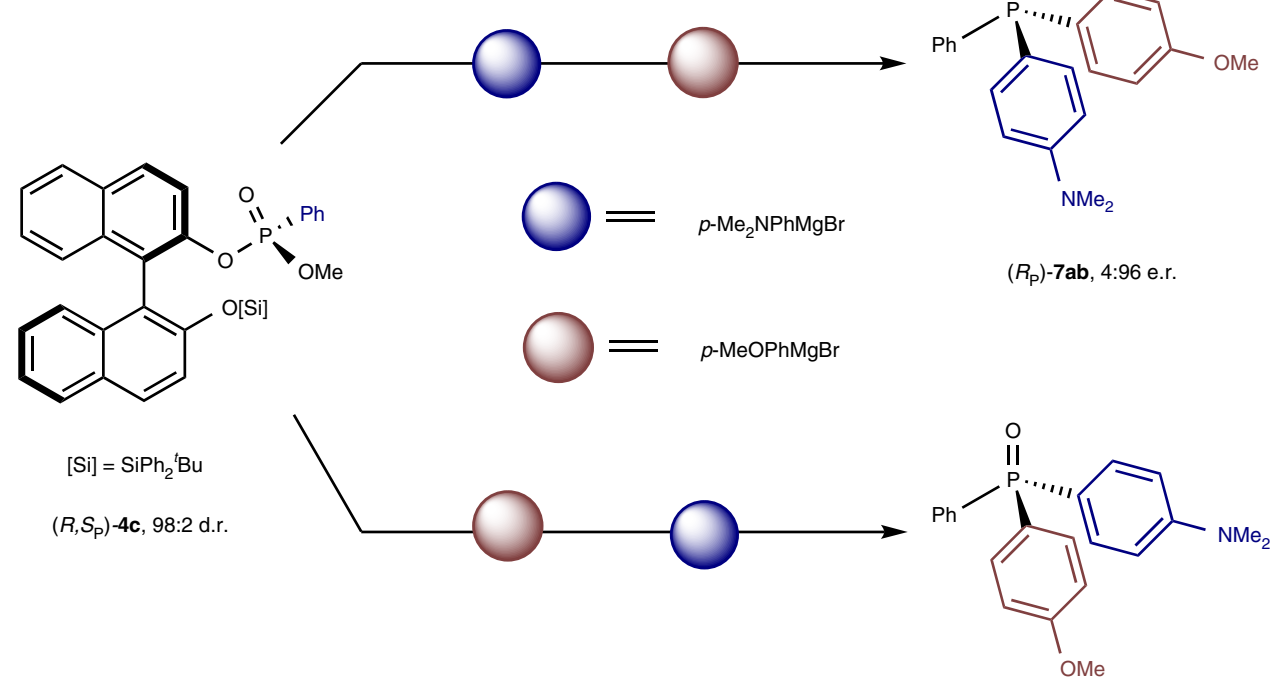

$\left(S_{\mathrm{p}}\right)-7 \mathrm{ab}, 95: 5$ e.r.<smiles>COc1ccc(P(C)(=O)c2ccccc2)cc1</smiles>

$\left(R_{\mathrm{p}}\right)-7 \mathrm{ae}, 95: 5$ e.r.

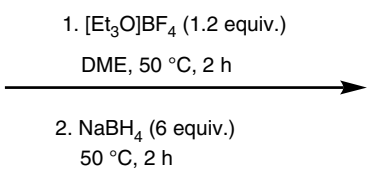

$50{ }^{\circ} \mathrm{C}, 2 \mathrm{~h}$

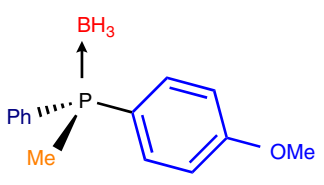

$\left(R_{\mathrm{P}}\right)-8 \mathrm{ae} \cdot \mathrm{BH}_{3}, 72 \%, 94: 6$ e.r.

Fig. 6 | Enantiodivergent synthesis of P-stereogenic phosphine oxides. a, Sequence-specific formation of both enantiomers of 7ab. b, Phosphine oxide reduction using sodium borohydride. DME, dimethoxyethane.

organolithium can successfully be applied, giving thiophene- and $t$-butyl-substituted phosphine oxides $\left(R_{\mathrm{P}}\right)-7$ af and $\left(R_{\mathrm{P}}\right)$-7ag in good yields and excellent enantioselectivity $(75 \%, 96: 4$ e.r. and $82 \%, 94: 6$ e.r., respectively). It should be noted that, in the case of sterically demanding $t$-BuLi, a slightly diminished enantioselectivity was observed (92:8 e.r.), which is attributed to epimerization of phosphinate by lithium methoxide generated as a by-product of the substitution reaction. However, using a reverse addition protocol, phosphine oxide $\left(R_{\mathrm{p}}\right)$-7ag was obtained with 94:6 e.r., opening a route to challenging homochiral bulky phosphines, which are highly privileged ligands in catalysis ${ }^{5-8}$. Although reduction protocols for phosphine oxides to phosphines are well established, we have shown that phosphine oxide $\left(R_{\mathrm{p}}\right)$-7ae was readily reduced to the corresponding phosphine isolated as the borane complex $\left(R_{\mathrm{P}}\right)$ $\mathbf{8 a} \cdot \mathrm{BH}_{3}$, without compromising its stereochemical integrity $(72 \%$, 94:6 e.r., Fig. 6b), using Meerwein's salt and $\mathrm{NaBH}_{4}$ (ref. ${ }^{58}$ ). Finally, we also demonstrated that, by simply switching the order of addition of the Grignard nucleophiles, this method could be used for the stereodivergent preparation of both enantiomers of P-chiral phosphine oxides starting from the same phosphonate enantiomer (Fig. 6a). For instance, each enantiomer of chiral phosphine oxide $7 \mathbf{a b}$ is generated from $\left(R, S_{\mathrm{P}}\right)-\mathbf{4} \mathbf{c}$ with excellent enantioselectivities (4:96 e.r. and 95:5 e.r.) by altering the addition sequence, illustrating the versatility and in particular flexibility to readily access various homochiral P-stereogenic phosphorus compounds.

\section{Conclusions}

Homochiral stereogenic phosphorus compounds are obtained through a Pd-catalysed asymmetric $\mathrm{C}-\mathrm{P}$ coupling reaction of aryl halides and phosphoramidites, by virtue of axial-to-central transfer of chirality involving the stereoselective formation of a unique phosphonium salt. The protocol uses readily available reagents and simple conditions and provides a flexible platform for the construction of a broad array of chiral P compounds. Cheap BINOL derivatives, used to achieve excellent stereocontrol, can be readily recovered with high enantiopurity. The isolation of a key intermediate revealed axial-to-central transfer of chirality involving the stereoselective formation of a unique phosphonium salt. The stereodivergent nature of the methodology was demonstrated by the preparation of both enantiomers of a phosphine oxide from a single phosphonate enantiomer by simply altering the addition sequence of organomagnesium reagents. We also solved some of the existing problems associated with the P-chiral compounds during a sequential substitution event with organolithium and organomagnesium reagents, such as complete double substitution of phosphinates and decrease of stereoselectivity during the substitution at $\mathrm{P}$ stereocentres. The methodology presented here to access various P-chirogenic compounds, in particular phosphines and phosphonates, could accelerate future developments in the fields of asymmetric catalysis and drug development.

\section{Methods}

General procedure for C-P coupling. A flame-dried Schlenk tube was charged with phosphoramidite $(R)-1 \mathbf{a}(0.13 \mathrm{~g}, 0.30 \mathrm{mmol}, 1.0$ equiv. $)$ or $(R)-1 \mathbf{b}(0.11 \mathrm{~g}$, $0.30 \mathrm{mmol}, 1.0$ equiv.), $\mathrm{Pd}_{2}(\mathrm{dba})_{3}(3.1 \mathrm{mg}, 3.0 \mu \mathrm{mol}, 1.0 \mathrm{~mol} \%), \mathrm{Cs}_{2} \mathrm{CO}_{3}(98 \mathrm{mg}$, $0.30 \mathrm{mmol}, 1.0$ equiv. $)$ and the corresponding aryl iodide $(0.30 \mathrm{mmol}, 1.0$ equiv. $)$. After three vacuum-nitrogen cycles, anhydrous toluene $(3.0 \mathrm{ml})$ was added and the reaction mixture was heated to 70 or $100^{\circ} \mathrm{C}$ for the appropriate time. Subsequently, the reaction mixture was cooled to room temperature and water $(3.0 \mathrm{ml})$ was added. After stirring for $10 \mathrm{~min}$, ethyl acetate $(3.0 \mathrm{ml})$ was added. The aqueous phase was extracted with ethyl acetate $(3 \times 1.5 \mathrm{ml})$. The combined organic phases were dried over $\mathrm{MgSO}_{4}$ and all volatiles were removed under reduced pressure. The crude product was purified using medium presure liquid chromatography (MPLC) with $n$-pentane/ethyl acetate as eluent. 
General procedure for the preparation of phosphinates 5a-e. A flame-dried Schlenk tube was charged with phosphonate $\left(R, S_{\mathrm{P}}\right)-4 \mathrm{c}(100 \mathrm{mg}, 0.147 \mathrm{mmol}, 1.0$ equiv.). After three vacuum-nitrogen cycles, a mixture of 1,4-dioxane/diethyl ether $(2: 1,2.9 \mathrm{ml})$ was added. Subsequently, the appropriate Grignard solution $(0.30 \mathrm{mmol}, 2.0$ equiv., $0.5 \mathrm{M})$ was added dropwise and the reaction mixture was stirred for the appropriate time at room temperature. After full conversion was observed by thin-layer chromatography (TLC), saturated aqueous $\mathrm{NH}_{4} \mathrm{Cl}$ solution $(2 \mathrm{ml})$ was added and the aqueous phase was extracted with ethyl acetate $(3 \times 1.5 \mathrm{ml})$. The combined organic phases were dried over $\mathrm{MgSO}_{4}$ and all volatiles were removed under reduced pressure. The crude product was purified using MPLC with dichloromethane/ethyl acetate as eluent.

\section{General procedure for the preparation of phosphine oxides using Grignard} reagents 7aa-ae. A flame-dried Schlenk tube was charged with the phosphinate $\left(R_{\mathrm{P}}\right)-5 \mathbf{a}(20 \mathrm{mg}, 76 \mu \mathrm{mol}, 1.0$ equiv.). After three vacuum-nitrogen cycles, 1,4-dioxane $(0.8 \mathrm{ml})$ was added. Subsequently, the appropriate Grignard solution $(0.30 \mathrm{mmol}, 4.0$ equiv.) was added dropwise and the reaction mixture was stirred for the appropriate time at room temperature. After full conversion was observed by TLC, saturated aqueous $\mathrm{NH}_{4} \mathrm{Cl}$ solution $(2 \mathrm{ml})$ was added and the aqueous phase was extracted with ethyl acetate $(3 \times 1.5 \mathrm{ml})$. The combined organic phases were dried over $\mathrm{MgSO}_{4}$ and all volatiles were removed under reduced pressure. The crude product was purified using MPLC with dichloromethane/ethyl acetate (80\%) as eluent.

General procedure for the preparation of phosphine oxides using organolithium reagents 7 af and 7ag. A flame-dried Schlenk tube was charged with phosphinate $\left(R_{\mathrm{P}}\right)-5 \mathrm{a}(20 \mathrm{mg}, 76 \mu \mathrm{mol}, 1.0$ equiv. $)$. After three vacuumnitrogen cycles, THF $(0.8 \mathrm{ml})$ was added. Subsequently, the appropriate organolithium reagent $(0.30 \mathrm{mmol}, 4.0$ equiv. $)$ was added dropwise at $-78{ }^{\circ} \mathrm{C}$ and the reaction mixture was stirred for the appropriate time. After full conversion was observed by TLC, saturated aqueous $\mathrm{NH}_{4} \mathrm{Cl}$ solution $(2 \mathrm{ml})$ was added and the aqueous phase was extracted with ethyl acetate $(3 \times 1.5 \mathrm{ml})$. The combined organic phases were dried over $\mathrm{MgSO}_{4}$ and all volatiles were removed under reduced pressure. The crude product was purified using MPLC with dichloromethane/ethyl acetate $(80 \%)$ as eluent or preparative TLC using the same eluent.

\section{Data availability}

Additional data can be found in the Supplementary Information. All data needed to evaluate the conclusions in the paper are present in the paper and/or the Supplementary Information. Additional data related to this paper may be requested from the authors upon reasonable request. Crystallographic data for the structures reported in this Article have been deposited at the Cambridge Crystallographic Data Centre, under deposition numbers CCDC $2086071\left(\left(R, S_{\mathrm{P}}\right)-\mathbf{2 a m}\right)$, CCDC $2086073\left(\left(R, S_{\mathrm{P}}\right)-3\right)$, CCDC $2086072\left(\left(R, S_{\mathrm{P}}\right)-4 \mathbf{c}\right)$, CCDC $2086068\left(\left(R_{\mathrm{P}}\right)-\mathbf{5 a}\right)$, CCDC $2086069\left(\left(S_{\mathrm{p}}\right)-7 \mathbf{a b}\right)$, CCDC $2086070\left(\left[\left(R, S_{\mathrm{p}}\right)\right.\right.$-2ab-Int $\left.] \mathrm{OTf}\right)$. Copies of the data can be obtained free of charge via https://www.ccdc.cam.ac.uk/structures/.

Received: 27 May 2021; Accepted: 30 September 2021; Published online: 23 December 2021

\section{References}

1. Knowles, W. S. Asymmetric hydrogenations (Nobel Lecture). Angew. Chem. Int. Ed. 41, 1998-2007 (2002).

2. Knowles, W. S. \& Sabacky, M. J. Catalytic asymmetric hydrogenation employing a soluble, optically active, rhodium complex. Chem. Commun. 1445-1446 (1968)

3. Noyori, R. Asymmetric Catalysis In Organic Synthesis (Wiley, 1994).

4. Crépy, K. V. L. \& Imamoto, T. Recent developments in catalytic asymmetric hydrogenation employing P-chirogenic diphosphine ligands. Adv. Synth. Catal. 345, 79-101 (2003).

5. Kamer, P. C. J. \& van Leeuwen, P. W. N. M. (eds) Design and Synthesis of Phosphite Ligands for Homogeneous Catalysis (John Wiley \& Sons, 2012).

6. Fernández-Pérez, H., Etayo, P., Panossian, A. \& Vidal-Ferran, A. Phosphinephosphinite and phosphine-phosphite Ligands: preparation and applications in asymmetric catalysis. Chem. Rev. 111, 2119-2176 (2011).

7. Tang, W. \& Zhang, X. New chiral phosphorus ligands for enantioselective hydrogenation. Chem. Rev. 103, 3029-3070 (2003).

8. Dutartre, M., Bayardon, J. \& Jugé, S. Applications and stereoselective syntheses of P-chirogenic phosphorus compounds. Chem. Soc. Rev. 45, 5771-5794 (2016).

9. Ma, Y.-N., Li, S.-X. \& Yang, S.-D. New approaches for biaryl-based phosphine ligand synthesis via $\mathrm{P}=\mathrm{O}$ Directed $\mathrm{C}-\mathrm{H}$ functionalizations. Acc. Chem. Res. 50, 1480-1492 (2017).

10. Xiao, Y., Sun, Z., Guo, H. \& Kwon, O. Chiral phosphines in nucleophilic organocatalysis. Beilstein J. Org. Chem. 10, 2089-2121 (2014).

11. Lagasse, F. \& Kagan, H. B. Chiral monophosphines as ligands for asymmetric organometallic catalysis. Chem. Pharm. Bull. 48, 315-324 (2000).

12. van den Berg, M. et al. Highly enantioselective rhodium-catalyzed hydrogenation with monodentate ligands. J. Am. Chem. Soc. 122, 11539-11540 (2000)
13. Reetz, M. T. \& Sell, T. Rhodium-catalyzed enantioselective hydrogenation using chiral monophosphonite ligands. Tetrahedron Lett. 41, 6333-6336 (2000).

14. Claver, C. et al. Biarylphosphonites: a class of monodentate phosphorus(III) ligands that outperform their chelating analogues in asymmetric hydrogenation catalysis. Chem. Commun. 961-962 (2000).

15. Joly, D. et al. White organic light-emitting diodes based on quench-resistant fluorescent organophosphorus dopants. Adv. Funct. Mater. 22, 567-576 (2012)

16. Lamberth, C. Amino acid chemistry in crop protection. Tetrahedron 66, 7239-7256 (2010)

17. Rodriguez, J. B. \& Gallo-Rodriguez, C. The role of the phosphorus atom in drug design. ChemMedChem 14, 190-216 (2019).

18. Kolodiazhnyi, O. I. Recent advances in asymmetric synthesis of $P$-stereogenic phosphorus compounds. Top. Curr. Chem. 360, 161-236 (2015).

19. Jordheim, L. P., Durantel, D., Zoulim, F. \& Dumontet, C. Advances in the development of nucleoside and nucleotide analogues for cancer and viral diseases. Nat. Rev. Drug Discov. 12, 447-464 (2013).

20. Eastman, R. T. et al. Remdesivir: a review of its discovery and development leading to emergency use authorization for treatment of COVID-19. ACS Cent. Sci. 6, 672-683 (2020).

21. Kupferschmidt, K. \& Cohen, J. WHO launches global megatrial of the four most promising coronavirus treatments. Science https://doi.org/10.1126/ science.abb8497 (2020).

22. Pietrusiewicz, K. M. \& Zablocka, M. Preparation of scalemic P-chiral phosphines and their derivatives. Chem. Rev. 94, 1375-1411 (1994).

23. Grabulosa, A., Granell, J. \& Muller, G. Preparation of optically pure $P$-stereogenic trivalent phosphorus compounds. Coord. Chem. Rev. 251, 25-90 (2007).

24. Kolodiazhnyi, O. I. Recent developments in the asymmetric synthesis of P-chiral phosphorus compounds. Tetrahedron: Asymmetry 23, 1-46 (2012).

25. Bergin, E. et al. Synthesis of P-stereogenic phosphorus compounds. Asymmetric oxidation of phosphines under Appel conditions. J. Am. Chem. Soc. 129, 9566-9567 (2007).

26. Kortmann, F. A. et al. Consecutive dynamic resolutions of phosphine oxides. Chem. Sci. 5, 1322-1327 (2014).

27. Bagi, P., Ujj, V., Czugler, M., Fogassy, E. \& Keglevich, G. Resolution of P-stereogenic P-heterocycles via the formation of diastereomeric molecular and coordination complexes (a review). Dalton Trans. 45, 1823-1842 (2016).

28. Xu, Q., Zhao, C.-Q. \& Han, L.-B. Stereospecific nucleophilic substitution of optically pure $H$-phosphinates: a general way for the preparation of chiral P-stereogenic phosphine oxides. J. Am. Chem. Soc. 130, 12648-12655 (2008).

29. Korpiun, O. \& Mislow, K. New route to the preparation and configurational correlation of optically active phosphine oxides. J. Am. Chem. Soc. 89, 4784-4786 (1967)

30. Juge, S., Stephan, M., Laffitte, J. A. \& Genet, J. P. Efficient asymmetric synthesis of optically pure tertiary mono and diphosphine ligands. Tetrahedron Lett. 31, 6357-6360 (1990).

31. Han, Z. S. et al. Efficient asymmetric synthesis of $P$-chiral phosphine oxides via properly designed and activated benzoxazaphosphinine-2-oxide agents. J. Am. Chem. Soc. 135, 2474-2477 (2013).

32. Corey, E. J., Chen, Z. \& Tanoury, G. J. A new and highly enantioselective synthetic route to P-chiral phosphines and diphosphines. J. Am. Chem. Soc 115, 11000-11001 (1993).

33. $\mathrm{Xu}, \mathrm{D}$. et al. Enantiodivergent formation of C-P bonds: synthesis of P-chiral phosphines and methylphosphonate oligonucleotides. J. Am. Chem. Soc. 142, 5785-5792 (2020)

34. Tappe, F. M. J., Trepohl, V. T. \& Oestreich, M. Transition-metal-catalyzed C-P cross-coupling reactions. Synthesis 2010, 3037-3062 (2010).

35. Zakirova, G. G., Mladentsev, D. Y. \& Borisova, N. E. Palladium-catalyzed C-P cross-coupling between (het)aryl halides and secondary phosphine oxides. Synthesis 51, 2379-2386 (2019)

36. Berger, O., Petit, C., Deal, E. L. \& Montchamp, J.-L. Phosphorus-carbon bond formation: palladium-catalyzed cross-coupling of $H$-phosphinates and other $\mathrm{P}(\mathrm{O}) \mathrm{H}$-containing compounds. Adv. Synth. Catal. 355, 1361-1373 (2013).

37. Kinbara, A., Ito, M., Abe, T. \& Yamagishi, T. Nickel-catalyzed C-P cross-coupling reactions of aryl iodides with $H$-phosphinates. Tetrahedron $\mathbf{7 1}$, 7614-7619 (2015)

38. Rout, L. \& Punniyamurthy, T. Recent advances in transition-metal-mediated $\mathrm{C}_{\mathrm{sp} 2}-\mathrm{B}$ and $\mathrm{C}_{\mathrm{sp} 2}-\mathrm{P}$ cross-coupling reactions. Coord. Chem. Rev. 431, 213675 (2020)

39. Chen, L., Liu, X.-Y. \& Zou, Y.-X. Recent advances in the construction of phosphorus-substituted heterocycles, 2009-2019. Adv. Synth. Catal. 362, 1724-1818 (2020)

40. Łastawiecka, E. et al. P-Arylation of secondary phosphine oxides catalyzed by nickel-supported nanoparticles. Org. Chem. Front. 5 , 2079-2085 (2018).

41. Moncarz, J. R., Laritcheva, N. F. \& Glueck, D. S. Palladium-catalyzed asymmetric phosphination: enantioselective synthesis of a P-chirogenic phosphine. J. Am. Chem. Soc. 124, 13356-13357 (2002). 
42. Julienne, D., Delacroix, O. \& Gaumont, A.-C. First study on the enantioselective palladium-catalyzed $\mathrm{C}-\mathrm{P}$ cross-coupling reaction between an alkenyltriflate and a phosphine-borane. C. R. Chim. 13, 1099-1103 (2010).

43. Brunker, T. J., Anderson, B. J., Blank, N. F., Glueck, D. S. \& Rheingold, A. L. Enantioselective synthesis of P-stereogenic benzophospholanes via palladium-catalyzed intramolecular cyclization. Org. Lett. 9, 1109-1112 (2007)

44. Koshti, V. S., Gote, R. P. \& Chikkali, S. H. Accelerated and enantioselective synthesis of a library of P-stereogenic urea phosphines. Eur. J. Org. Chem. 2018, 6768-6779 (2018).

45. Korff, C. \& Helmchen, G. Preparation of chiral triarylphosphines by Pd-catalysed asymmetric P-C cross-coupling. Chem. Commun. 530-531 (2004).

46. Wang, C. et al. Synthesis of P-chiral phosphine compounds by palladium-catalyzed C-P coupling reactions. Chem. Commun. 56, 11775-11778 (2020).

47. Beaud, R., Phipps, R. J. \& Gaunt, M. J. Enantioselective Cu-catalyzed arylation of secondary phosphine oxides with diaryliodonium salts toward the synthesis of P-chiral phosphines. J. Am. Chem. Soc. 138, 13183-13186 (2016).

48. Dai, Q., Li, W., Li, Z. \& Zhang, J. P-Chiral phosphines enabled by palladium/ Xiao-Phos-catalyzed asymmetric P-C cross-coupling of secondary phosphine oxides and aryl bromides. J. Am. Chem. Soc. 141, 20556-20564 (2019).

49. Dai, Q., Liu, L., Qian, Y., Li, W. \& Zhang, J. Construction of P-chiral alkenylphosphine oxides through highly chemo-, regio-, and enantioselective hydrophosphinylation of alkynes. Angew. Chem. Int. Ed. 59, 20645-20650 (2020)

50. Teichert, J. F. \& Feringa, B. L. Phosphoramidites: privileged ligands in asymmetric catalysis. Angew. Chem. Int. Ed. 49, 2486-2528 (2010).

51. Feringa, B. L. Phosphoramidites: marvellous ligands in catalytic asymmetric conjugate addition. Acc. Chem. Res. 33, 346-353 (2000).

52. Imrie, C. et al. Structural study on quasi-phosphonium salts containing phosphorus-oxygen, phosphorus-oxygen, phosphorus-nitrogen and phosphorus-sulphur bonds. J. Phys. Org. Chem. 8, 41-46 (1995).

53. Kenny, N. P., Rajendran, K. V. \& Gilheany, D. G. Chemoselective reduction of the phosphoryl bond of $\mathrm{O}$-alkyl phosphinates and related compounds: an apparently impossible transformation. Chem. Commun. 51, 16561-16564 (2015).

54. Melvin, L. S. An efficient synthesis of 2-hydroxyphenylphosphonates. Tetrahedron Lett. 22, 3375-3376 (1981).

55. Hatano, M., Miyamoto, T. \& Ishihara, K. 3,3'-Diphosphoryl-1,1'-bi-2-naphthol$\mathrm{Zn}$ (II) complexes as conjugate acid-base catalysts for enantioselective dialkylzinc addition to aldehydes. J. Org. Chem. 71, 6474-6484 (2006).

56. Kendall, A. J., Salazar, C. A., Martino, P. F. \& Tyler, D. R. Direct conversion of phosphonates to phosphine oxides: an improved synthetic route to phosphines including the first synthesis of methyl JohnPhos. Organometallics 33, 6171-6178 (2014).
57. Adams, H., Collins, R. C., Jones, S. \& Warner, C. J. A. Enantioselective preparation of $P$-chiral phosphine oxides. Org. Lett. 13, 6576-6579 (2011). 58. Rajendran, K. V. \& Gilheany, D. G. Simple unprecedented conversion of phosphine oxides and sulfides to phosphine boranes using sodium borohydride. Chem. Commun. 48, 817-819 (2012).

\section{Acknowledgements}

This work was financially supported by the Nederlandse Organisatie voor Wetenschappelijk Onderzoek, Grant Number: 718,015,004 (to A.M.), the European Research Council (ERC advanced grant 694345) and the Dutch Ministry of Education, Culture and Science (Gravitation programme 024.001.035) (to B.L.F.). N.O.T. is grateful for financial support from the German Research Foundation (DFG, TH2510/1-1). R. Sneep is acknowledged for performing the high resolution mass spectrometry and M. Ovalle for his help in designing the graphics. We thank A. S. Lubbe and R. Costil for important suggestions.

\section{Author contributions}

A.M. initiated the project with preliminary experiments. A.M., N.O.T. and R.D. optimized the reaction. The scope was evaluated by A.M. and N.O.T. with the help of R.D. The project was supervised by B.L.F. who also guided the research. X-ray suitable crystals were grown by A.M. and N.O.T. and their structures were solved and refined by A.M. The manuscript and supporting information was written by A.M., N.O.T. and B.L.F. with help and suggestions from R.D.

\section{Competing interests}

The authors declare no competing interests.

\section{Additional information}

Supplementary information The online version contains supplementary material available at https://doi.org/10.1038/s41929-021-00697-9.

Correspondence and requests for materials should be addressed to Ben L. Feringa.

Peer review information Nature Catalysis thanks Junliang Zhang and the other, anonymous, reviewer(s) for their contribution to the peer review of this work.

Reprints and permissions information is available at www.nature.com/reprints.

Publisher's note Springer Nature remains neutral with regard to jurisdictional claims in published maps and institutional affiliations.

(C) The Author(s), under exclusive licence to Springer Nature Limited 2021 